Subscriber access provided by École de technologie supérieure. Service de la bibliothèque

\title{
Article
}

\section{Blending and morphology control to turn highly hydrophobic SEBS electrospun mats superhydrophilic}

\author{
Rafael Salles Kurusu, and Nicole Raymonde Demarquette \\ Langmuir, Just Accepted Manuscript • DOI: 10.1021/acs.langmuir.5b00814 • Publication Date (Web): 25 Apr 2015 \\ Downloaded from http://pubs.acs.org on May 1, 2015
}

\section{Just Accepted}

"Just Accepted" manuscripts have been peer-reviewed and accepted for publication. They are posted online prior to technical editing, formatting for publication and author proofing. The American Chemical Society provides "Just Accepted" as a free service to the research community to expedite the dissemination of scientific material as soon as possible after acceptance. "Just Accepted" manuscripts appear in full in PDF format accompanied by an HTML abstract. "Just Accepted" manuscripts have been fully peer reviewed, but should not be considered the official version of record. They are accessible to all readers and citable by the Digital Object Identifier (DOI®). "Just Accepted" is an optional service offered to authors. Therefore, the "Just Accepted" Web site may not include all articles that will be published in the journal. After a manuscript is technically edited and formatted, it will be removed from the "Just Accepted" Web site and published as an ASAP article. Note that technical editing may introduce minor changes to the manuscript text and/or graphics which could affect content, and all legal disclaimers and ethical guidelines that apply to the journal pertain. ACS cannot be held responsible for errors or consequences arising from the use of information contained in these "Just Accepted" manuscripts. 
This document is the Accepted Manuscript version of a Published Work that appeared in final form in Langmuir 2015, vol. $31 \mathrm{no} 19$, pp. 5495-5503, copyright ( $\odot$ American Chemical Society after peer review and technical editing by the publisher. To access the final edited and published work see http://dx.doi.org/10.1021/acs.langmuir.5b00814.

\title{
Blending and morphology control to turn highly
}

\author{
hydrophobic SEBS electrospun mats
}

\author{
superhydrophilic
}

\author{
Rafael S. Kurusu, Nicole R. Demarquette* \\ *Mechanical Engineering Department, École de technologie supérieure - ÉTS, \\ 1100 Notre-Dame Street West, Montréal, Québec - Canada H3C 1K3
}

\begin{abstract}
Thermoplastic elastomer SEBS, a triblock copolymer composed of styrene (S) and ethylene-co-butylene (EB) blocks, can be dissolved and processed by electrospinning to produce flexible non-woven mats that can be interesting for applications like filtration or separation membranes. Controlling surface properties such as hydrophobicity/hydrophilicity is critical to achieving a desired performance. In this study, highly hydrophobic electrospun SEBS mats were obtained, following which an amphiphilic molecule (Pluronic ${ }^{\circledR}$ F127) was solutionblended with SEBS prior to electrospinning, in a bid to produce a hydrophilic membrane. The result was a fast-spreading superhydrophilic mat with thinner fibers that preserved the flexibility
\end{abstract}


of the SEBS. The morphologies of non-woven mats, flat films (prepared by dip-coating using identical solutions) and of the surface of individual fibers were characterized using different microscopy techniques (Optical, SEM and AFM). Chemical analysis by X-ray Photoelectron Spectroscopy (XPS) revealed a large F127 concentration in the outermost surface layer. In addition, an analysis of dip-coated flat films revealed that for $20 \mathrm{wt} \%$ of F127 there was a change in the blend morphology from dispersed F127-rich regions in the SEBS matrix to an interconnected phase homogenously distributed across the film that resembled grain boundaries of micellar crystals. Our results indicated that this morphology change at $20 \mathrm{wt} \%$ of F127 also occurred to some extent in the electrospun fibers and this, combined with the large surface area of the mats, led to a drastic reduction in the contact angle and fast water absorption, turning highly hydrophobic electrospun mats superhydrophilic.

\section{INTRODUCTION}

In a typical electrospinning experiment, a polymer solution inside a syringe is charged by connecting the syringe needle to a high voltage supply, and, in optimal conditions, a drop on the tip of the needle is deformed into a conic shape, and then a thin jet erupts and moves towards a grounded collector. Interactions between charges cause bending instabilities, reducing the diameter of the jet while the solvent evaporates. Finally, solid fibers are deposited on the collector $^{1,2}$. The result is a porous non-woven mat with randomly aligned fibers and a high superficial area. These mats can find many possible applications in tissue engineering, filtration, separation membranes, etc ${ }^{3,4,5}$. In all cases, the control of surface properties such as hydrophobicity/hydrophilicity is important to achieve a desired performance. As an example, in the event of an oil spill, a hydrophobic and oleophilic electrospun membrane can be used for 
filtration or adsorption in an oil-water system ${ }^{6,7,8}$. Hydrophilic scaffolds can have non-fouling properties that are interesting for applications such as affinity membranes ${ }^{9}$. Both superhydrophobicity and superhydrophilicity can be used as two different approaches to make self-cleaning mats ${ }^{10,11}$, often inspired by nature's examples such as lotus or ragwort leaves, and the pitcher plant ${ }^{12,13,14,15}$.

Electrospun mats have rough surfaces that can amplify the natural hydrophobicity or hydrophilicity of a material ${ }^{16,17}$, by either enhancing the effect of chemical composition with greater surface area, or by producing a composite surface of polymer and trapped air or liquid, according to wetting theories ${ }^{18,19,20}$. There are many examples of hydrophobization after electrospinning ${ }^{7,16,21,22}$. Combining micro (mat surface) and nanotexture (fiber surface) usually leads to high water contact angle values ${ }^{16,21}$, and even naturally hydrophilic polymers can produce hydrophobic surfaces by electrospinning ${ }^{23}$. Although less frequently reported, hydrophilization can also be achieved after electrospinning with a naturally hydrophilic polymer such as Polycaprolactone (PCL) $)^{24}$.

Another approach used to control the wetting properties of electrospun mats involves a posttreatment. Chemical vapor deposition ${ }^{25}$ or silanization ${ }^{26}$ can be used for hydrophobization. Hydrophilic mats can be also obtained after chemical vapor deposition or plasma treatment ${ }^{27,28}$, solution coating ${ }^{17,29}$, immersion precipitation ${ }^{30}$, cross-linking ${ }^{31}$ and heat treatment ${ }^{32}$. However, in these cases, there is a large increase in the cost and time needed to obtain the ideal surface condition.

Polymer blending can be a practical one-step alternative in producing superhydrophobic ${ }^{22}$, hydrophilic $^{33,34}$ and superhydrophilic mats ${ }^{24,34,35,36,37}$. In the case of surface hydrophilization, the strategies used involve either incorporating a hydrophilic polymer such as polyvinyl alcohol 
$(\mathrm{PVA})^{24,37}$ and poly(vinyl methyl ether) $(\mathrm{PVME})^{36}$ or an amphiphilic polymer such as the copolymers of poly(ethylene oxide)- $b$-poly(propylene oxide)- $b$-poly(ethylene oxide) (PEO-PPOPEO), known as Poloxamers, or commercially as Pluronics ${ }^{34,35}$. These polymers contain hydrophobic PPO as the mid-block and hydrophilic PEO as the end-blocks. The idea is that the hydrophobic segment will help anchor the molecule to the polymer matrix while hydrophilic segments will be active at the surface when in contact with water ${ }^{38,39}$. Vasita et al. obtained superhydrophilic mats of Poly(lactide-co-glycolide) (PLGA) by blending it with Pluronic F108. This effect was caused by an increased concentration of F108 at the surface, but the fiber morphology analysis revealed no phase separation between the two polymers at low concentrations $^{35}$. Liu et al. also obtained superhydrophilic mats by blending poly ( $\varepsilon^{-}$ caprolactone-co-lactide) with Pluronic F127, used for tissue engineering applications ${ }^{34}$.

Despite these examples, there is still a lack of understanding of blend morphology as a key factor for the hydrophilization of electrospun fibers with Pluronics. Furthermore, Pluronics can self-assemble to form micelles in solution as a function of temperature and concentration ${ }^{40,41}$. These micelles can form agglomerates with different morphologies, and then lead to the formation of a crystalline phase due to micelle crowding ${ }^{42,43}$.

In this work, linear triblock copolymer Styrene- $b$-ethylene-butylene- $b$-styrene (SEBS) was used to produce electrospun mats with different wetting behaviors. SEBS is interesting for electrospinning as it can be dissolved in different solvents, and the mechanical behavior of the resulting fibers is similar to that of elastomers. Pure SEBS and blends with different concentrations of PEO-PPO-PEO (Pluronic F127) were prepared in order to obtain a hydrophilic mat. Dip-coated flat films were prepared for comparison. Water contact angle measurements were carried out and explained based on the morphology of electrospun mats and films at the 
micron scale, chemical composition, segregation of the minor component to the surface and blend surface morphology at the sub-micron scale. To our knowledge, this is the first study on a phase-separated system with amphiphilic polymer (Pluronic) revealing the effect of blend morphology on the hydrophilicity of electrospun mats.

\section{EXPERIMENTAL}

Linear Triblock copolymer SEBS (G1652) with an average molecular weight of 79,000 g/mol and $30 \mathrm{wt} \%$ of styrene (S) blocks was kindly supplied by Kraton. Block copolymer PEO-PPOPEO (Pluronic F127) with an average molecular weight of 12,600 g/mol and $73.2 \mathrm{wt} \%$ of ethylene glycol blocks was purchased from Sigma Aldrich. Chloroform and Toluene were purchased from Fisher Scientific.

A mixture of chloroform and toluene $(80 / 20 \mathrm{wt} \%)^{44,45}$ was used as the solvent and incorporated into a previously weighed dry mixture of SEBS/F127 at different ratios, with a constant total concentration polymer/solution of $15 \mathrm{wt} \%$. The solutions were stirred vigorously for 15 minutes at room temperature until there was no sign of SEBS or F127 agglomeration. Following that, the solutions were either used for dip-coating or transferred to a syringe for electrospinning. Six compositions were studied: pure SEBS, SEBS/F127_5 (95/05 wt\%), SEBS/F127_10 (90/10 wt $\%)$, SEBS/F127_15 (85/15 wt\%), SEBS/F127_20 (80/20 wt\%) and pure F127. Blends containing higher concentrations of F127 were also tested, but then the process became unstable and heterogeneous mats were obtained.

A Dip-Master 50 dip-coater (Chemat Technology) was used for dip-coating glass slides with a residence time of 3 seconds and speed of $10 \mathrm{~mm} / \mathrm{min}$. For the electrospinning experiments, each syringe was placed in a syringe pump (PHD Ultra 4400, Harvard Apparatus), and the needle was 
charged using a power source SL40*150 (Spellman). A metallic plate covered with aluminum foil was used to collect the mats composed of randomly aligned fibers. The parameters used were: voltage of $15 \mathrm{kV}$, flow rate of $2 \mathrm{~mL} / \mathrm{h}$, distance to collector of $15 \mathrm{~cm}, 21 \mathrm{G}$ syringe needle, room temperature $\left(24^{\circ} \mathrm{C}\right)$ and $30 \%$ of relative humidity.

Water contact angle (WCA) values were obtained using a VCA Optima (AST products, Inc.) and Milli-Q ultrapure water. A total of eight measurements were carried out in different regions of each sample.

Scanning electron microscopy (SEM) was performed with a S3600N microscope (Hitachi) in secondary electron mode with $5 \mathrm{kV}$ of voltage. Prior to the analysis, the surfaces were coated with gold using a K550X sputter coater (Emitech). Films were also characterized by transmitted light microscopy with a BX51 optical microscope (Olympus). Atomic force microscopy (AFM) was performed with a FastScan Microscope (Bruker) with a Nanoscope V Controller in tapping mode, using medium oscillation damping with $300 \mathrm{KHz}$ of resonance frequency. Electrospun fibers were deposited on glass slides, and then individual fibers were imaged by carefully bringing the AFM tip in contact with this fiber prior to scanning. An etched Si cantilever (model ACTA from APPNano Inc.) was employed. Four scans in different fibers were performed for each sample. ImageJ software was used for image analysis of the micrographs.

The chemical composition of the materials was analyzed by X-ray Photoelectron Spectroscopy (XPS) using an ESCALAB 3 MKII (VG) with a Mg K $\alpha$ source and 216 watts of power. The depth of analysis was 50-100 Angstroms and the surface area analyzed was $2 \mathrm{mmx} 3 \mathrm{~mm}$ for each sample.

Tensile tests of the electrospun mats were performed with an ElectroForce ${ }^{\circledR} 3100$ test instrument (Bose) with a $22 \mathrm{~N}$ load cell. Rectangular specimens measuring $16 \mathrm{mmx} 0.5 \mathrm{~mm}$ were 
cut from each mat and the thickness measured using a micrometer. Five specimens of two compositions (pure SEBS and SEBS/F127_20) were tested. The distance between grips was kept at $4 \mathrm{~mm}$ and the speed of testing was $40 \mathrm{~mm} / \mathrm{min}$. Due to equipment and configuration limitations, the maximum possible elongation at break was $300 \%$.

\section{RESULTS AND DISCUSSION}

Figure 1 presents the water contact angle values and respective error bars for the electrospun mats as a function of F127 bulk concentration. Pure SEBS produced a highly hydrophobic mat with $139^{\circ} \pm 2$ contact angle. The mats with 5 and $10 \mathrm{wt} \%$ F127 remained highly hydrophobic, just like pure SEBS, until complete evaporation of the droplet. When the amount of F127 reached 15 $\mathrm{wt} \%$, the contact angle measured remained around $140^{\circ}$ instantly after the deposition, but then, the droplet impregnated the mat and the final angle was $0^{\circ}$, making it superhydrophilic. The time for this absorption varied between 10 seconds and 2 minutes depending on the region of the mat, which revealed heterogeneous surface properties for this composition. When the amount of F127 was further increased to $20 \mathrm{wt} \%$, the mat became homogeneously superhydrophilic, with fast spreading of water in all regions tested. Figure 2 shows that the absorption for the SEBS/F127_20 started at the moment the drop touched the mat ( $\mathrm{t}=0$ s in Figure 2), and after released from the needle the spreading occurred in fractions of a second. Mat morphology was then investigated in order to understand this drastic drop in contact angle. It is worth noting that it was impossible to obtain electrospun fibers with pure F127. Even at high concentrations (50$60 \mathrm{wt} \%$ ), electrospraying took place, possibly due to improper rheological properties considering the low molar mass of F127 


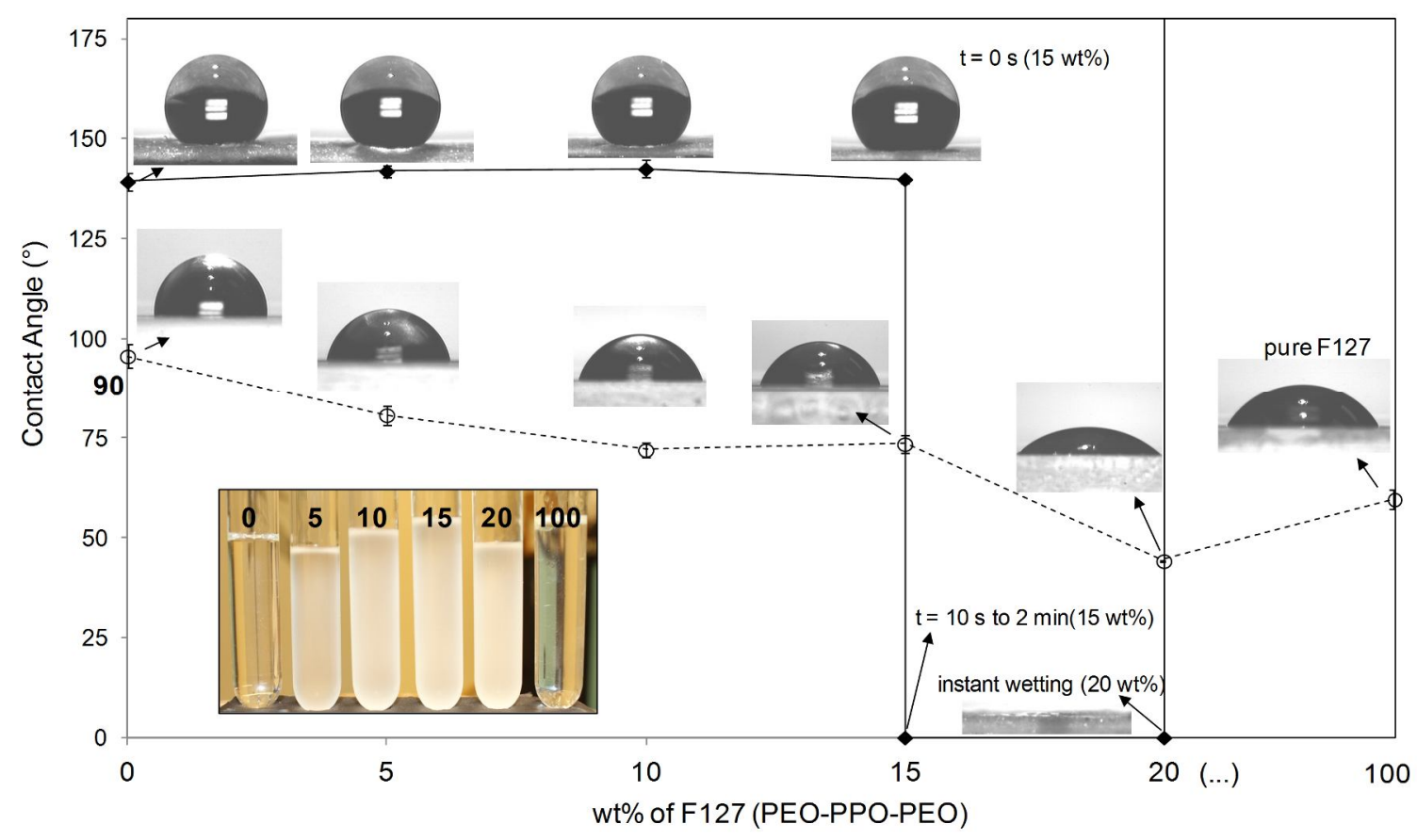

Figure 1 - Water contact angle for the electrospun mats (-) and dip-coated films (-๑) as a function of F127 concentration in the SEBS/F127 blends. The insert shows the vials containing each solution.

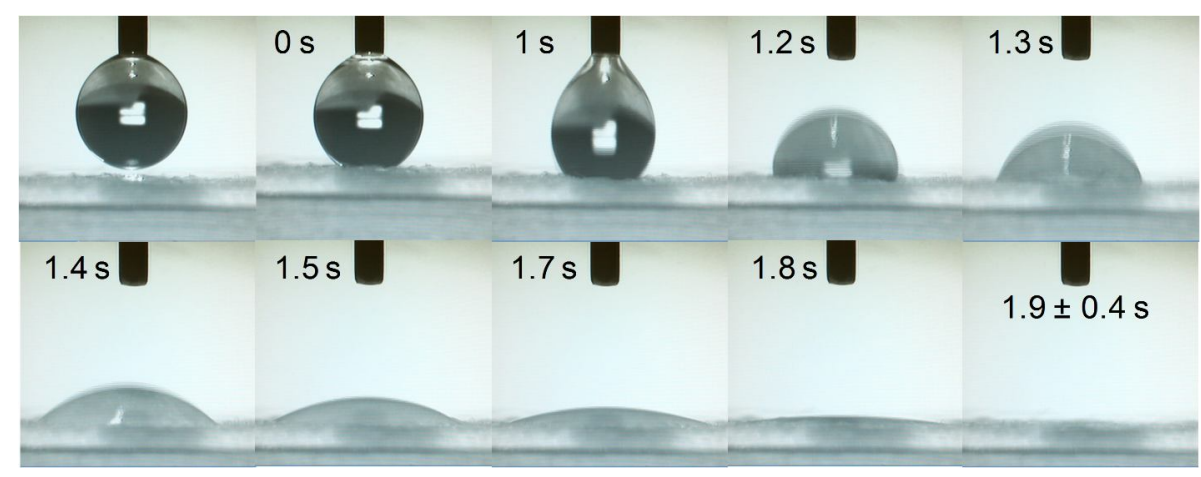

Figure 2 - Water droplet fast spreading for the superhydrophilic SEBS/F127_20 electrospun mat. 


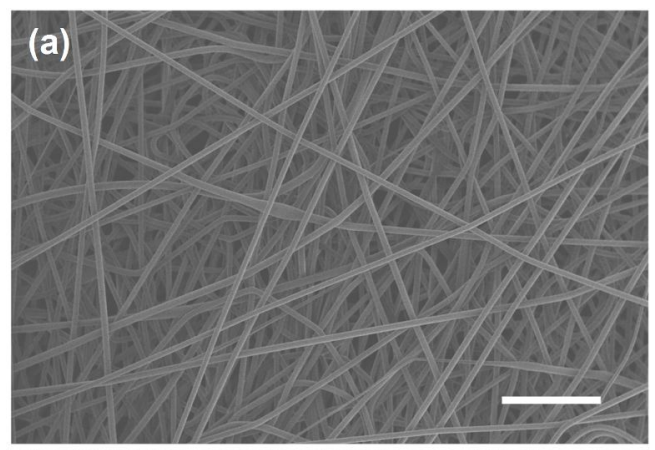

Figure 3 shows an overview of pure SEBS and SEBS/F127_20 mats. The most remarkable difference on mat morphology between pure SEBS and the blends is the reduction in fiber diameter, regardless of F127 percentage. The average fiber diameter for pure SEBS was $11.4 \pm 1.0 \mu \mathrm{m}$, and in the presence of $5,10,15$ and $20 \mathrm{wt} \%$ of $\mathrm{F} 127$ was $5.2 \pm 0.3 \mu \mathrm{m}, 4.9 \pm 0.5 \mu \mathrm{m}$, $4.4 \pm 0.4 \mu \mathrm{m}$ and $4.9 \pm 0.6 \mu \mathrm{m}$, respectively. A rough estimate made by $2 \mathrm{D}$ image analysis showed that there was also a consequent pore size reduction following the same trend of fiber diameter. The simple incorporation of additives can change solution properties like viscosity ${ }^{46}$ and influence fiber stretching during electrospinning. Similar results on SEBS fiber diameter reduction were reported by Rungswang et al. ${ }^{46}$, but in this case with a different additive.

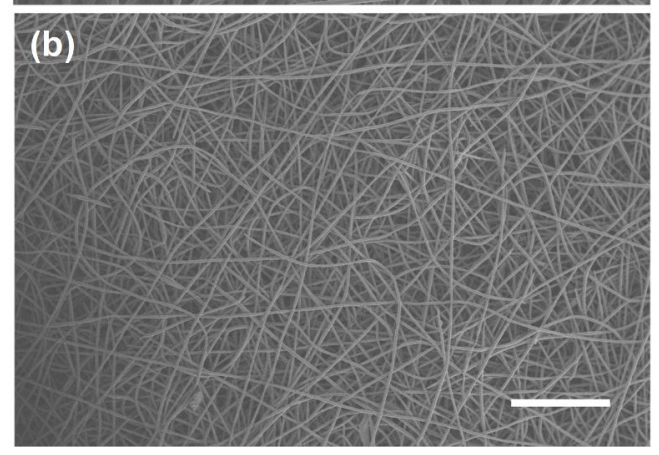

Figure 3 - Electrospun fibers observed by SEM with 100x magnification: (a) pure SEBS and (b) SEBS/F127_20. Scale bars correspond to $200 \mu \mathrm{m}$. 
Since all F127-containing electrospun mats (5, 10, 15 and $20 \mathrm{wt} \%)$ presented similar and homogeneous morphological features at the micron scale, there is no apparent correlation between mat morphology and water contact angle results. To understand the system SEBS/F127 without the typical rough surface of electrospun mats, identical solutions were dip-coated and tested. The results are also presented in Figure 1, showing that dip-coated pure SEBS had a contact angle of $96 \pm 3^{\circ}$, while the electrospun mat had a contact angle of $139 \pm 2^{\circ}$. Increasing the amount of F127 in the dip-coated blends led to an expected decrease in the contact angle values to $81 \pm 2^{\circ}, 72 \pm 2^{\circ}$ and $73 \pm 2^{\circ}$ for SEBS/F127_5, SEBS/F127_10 and SEBS/F127_15, respectively. There was a greater decrease in contact angle for the SEBS/F127_20 flat film $\left(44^{\circ} \pm 0.2\right)$, and this value was remarkably smaller than that of pure F127 $\left(60^{\circ} \pm 1\right)$, i.e., the dip-coated film with 20 wt $\%$ of F127 was more hydrophilic than the film of pure F127. This can indicate that when the amount of F127 reached $20 \mathrm{wt} \%$ there was a higher concentration of hydrophilic segments (PEO blocks) at the surface. Similar minimum values for water contact angle (around $44^{\circ}$ ) were reported for membranes containing Pluronic F127 blended in different polymer matrices, revealing a possible surface saturation ${ }^{38,39}$.

As mentioned earlier, roughness can contribute to amplifying the hydrophilic or hydrophobic character of a given material by increasing the contact area with the droplet (Wenzel state) or by creating a composite structure of the material and trapped air (Cassie-Baxter state) ${ }^{18,19,20}$. The rough surface of electrospun SEBS is what accounts for the hydrophobic character of the mats with up to 10 wt $\%$ of F127, compared to the dip-coated films. The large surface area and capillary action must also have contributed to the superhydrophilic effect of the blends with 15 and $20 \mathrm{wt} \%$ of F127, but the differences in water absorption time (inconstant for the SEBS/F127_15 mats; constant and fast for SEBS/F127_20 mats) cannot be fully explained by 
roughness alone. SEBS/F127_15 must have a heterogeneous chemical composition or fiber morphology to explain the inconsistency in absorption times. Based solely on contact angle measurements, fast-spreading SEBS/F127_20 seems to be homogeneous. XPS tests were therefore performed to understand the influence of the surface chemical composition.

Since Oxygen atoms are only present in the F127 molecules, a broad survey by XPS can provide information about the presence of this element at the surface of films and fibers. Based on the chemical structure and bulk composition, the amount (wt\%) of F127 was calculated, and is presented in Figure $4 \mathrm{a}$ as a function of bulk composition. For the dip-coated films with a bulk composition of 5 and $10 \mathrm{wt} \%$ F127, the surface composition had around $70 \mathrm{wt} \%$ F127. The F127 surface concentration for the SEBS/F127_15 film was almost $90 \mathrm{wt} \%$, and practically $100 \mathrm{wt} \%$ for the SEBS/F127_20 film. Electrospun mats also presented a significant F127 surface enrichment, but to a lesser extent compared to the dip-coated films. The bulk compositions of 5, 10, 15 and $20 \mathrm{wt} \%$ presented surface compositions of $23,38,58$ and $70 \mathrm{wt} \%$, respectively. Figure $4 \mathrm{~b}$ shows a sequence of typical high resolution spectra of the electrospun mats as a function of F127 concentration from $5 \mathrm{wt} \%$ to $20 \mathrm{wt} \%$. The increase in intensity for the ether carbon peak (-C-O-) at $286.6 \mathrm{eV}$ confirmed the surface enrichment, given that this type of bond is only found in F127 molecules. For the dip-coated films, the trend was the same, but with a higher intensity for the ether carbon peak. However, in all cases, it is not possible to tell the difference between hydrophilic PEO segments and hydrophobic PPO segments, as both contain oxygen and the same types of $\mathrm{C}-\mathrm{C}$ and $\mathrm{C}-\mathrm{O}$ bonds.

F127 molecules have a tendency to segregate at the surface due to incompatibility with SEBS. PPO blocks anchor the F127 molecule to the hydrophobic surface of SEBS and brushlike PEO segments extend in contact with water ${ }^{38,47}$. At first, PPO blocks with lower surface energy tend 
to segregate to the air surface while PEO blocks with higher surface energy are buried in the polymer matrix. Once the surface is in contact with an aqueous medium, hydrophilic PEO segments will extend and enrich the surface ${ }^{47}$. Still, chemical composition alone does not fully explain the difference in wetting properties between SEBS/F127_15 and SES/F127_20. Therefore, blend morphology was investigated.

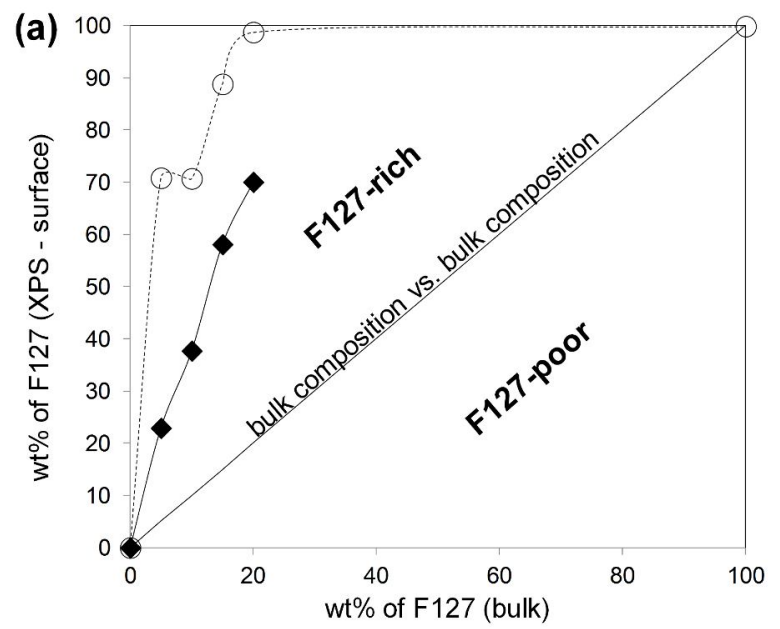

\section{(b)}
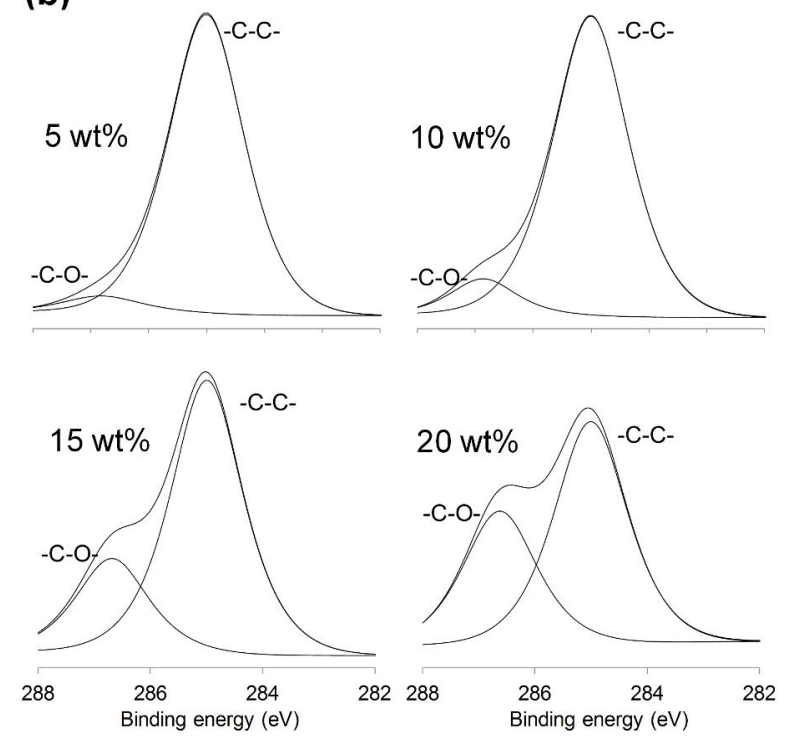

Figure 4 - XPS results: (a) Measured \% of oxygen atoms converted in wt\% of F127 vs. bulk wt\% of F127 for the electrospun mats ( $\bullet$ ) and dip-coated films (-๑)); (b) High resolution XPS spectra for the electrospun SEBS/F127 mats with 5, 10, 15 and $20 \mathrm{wt} \%$ of F127. 
Figure 5 presents the images obtained by transmitted light microscopy for the dip-coated films. There was always phase separation regardless of the concentration, confirmed by DSC results (not shown here). The blend with 5 wt\% of F127 (Figure 5b) presented a typical dispersed phase in the SEBS matrix, with the droplet diameter ranging from 0.5 to $5 \mu \mathrm{m}$. With $10 \mathrm{wt} \%$ of F127 (Figure 5c), the film contained a combination of the previously observed dispersed phase and larger domains of different morphology, with the diameter ranging from 10 to $30 \mu \mathrm{m}$. These domains are formed either by coalescence of smaller domains or by concentration fluctuations. SEBS/F127_15 (Figure 5d) presented similar features, but with larger domains containing the distinct morphology. With $20 \mathrm{wt} \%$ of F127 (Figure 5e), there was a complete switch to an interconnected morphology, replacing the previous dispersed phase, with grain-like regions having a diameter of about $10 \mu \mathrm{m}$, and surrounded by an interconnected phase that resembled grain boundaries with a thickness of approximately $1 \mu \mathrm{m}$ (Figure 5e). This unique morphology was observed evenly across the entire film. Pure F127 dip-coated film (Figure 5f) also presented a grain-like structure, but with smaller grains. At smaller magnifications (not shown here), pure F127 presented a spherulitic morphology. Figure 6 shows the surface topography of SEBS/F127_20 (Figure 6a) and pure F127 (Figure 6b) flat films using SEM in secondary electrons mode. The blend presented a rougher surface compared to pure F127. Considering that the chemical composition is practically the same, this roughness increase may explain the lower contact angle values for the blend.

The change in morphology possibly occurred due to a particular self-organization of F127 micelles with SEBS at around 80/20 wt $\%$. Micelle agglomeration in different structures occurs in solution due to increased concentration, and can lead to the formation of crystalline structures 
similar to those observed for SEBS/F127_20 and pure F127 $7^{40,41,42,43}$. Depending on the size of the agglomerates, colloidal dispersions can scatter light, and are therefore usually turbid when viewed with the naked eye. The insert in Figure 1 shows that all the solutions containing SEBS and F127 presented the typical turbidity of colloidal dispersions. Clear solutions were observed for pure SEBS and pure F127. Since identical solutions were used in dip-coating and electrospinning, from the original concentration to the complete absence of solvent, it was expected that any change in colloidal agglomeration due to different concentrations would affect the outcome of both techniques. The main difference lies in the order of magnitude of the structures formed during evaporation in each case. In dip-coating, the surface area in contact with air is much smaller, so that evaporation takes more time to occur. F127 molecules and micelles have mobility for a longer time period, increasing self-assembly and agglomeration in ordered structures. In electrospinning, jet stretching provides a greater contact area with air and facilitates evaporation ${ }^{2}$, leaving less time for self-organization. The fibers are solid before reaching the collector. Given that the fiber diameter is smaller than the grain-like structures observed in the flat films, the combined micelles of F127 and SEBS must have organized themselves in a different crystalline structure. 

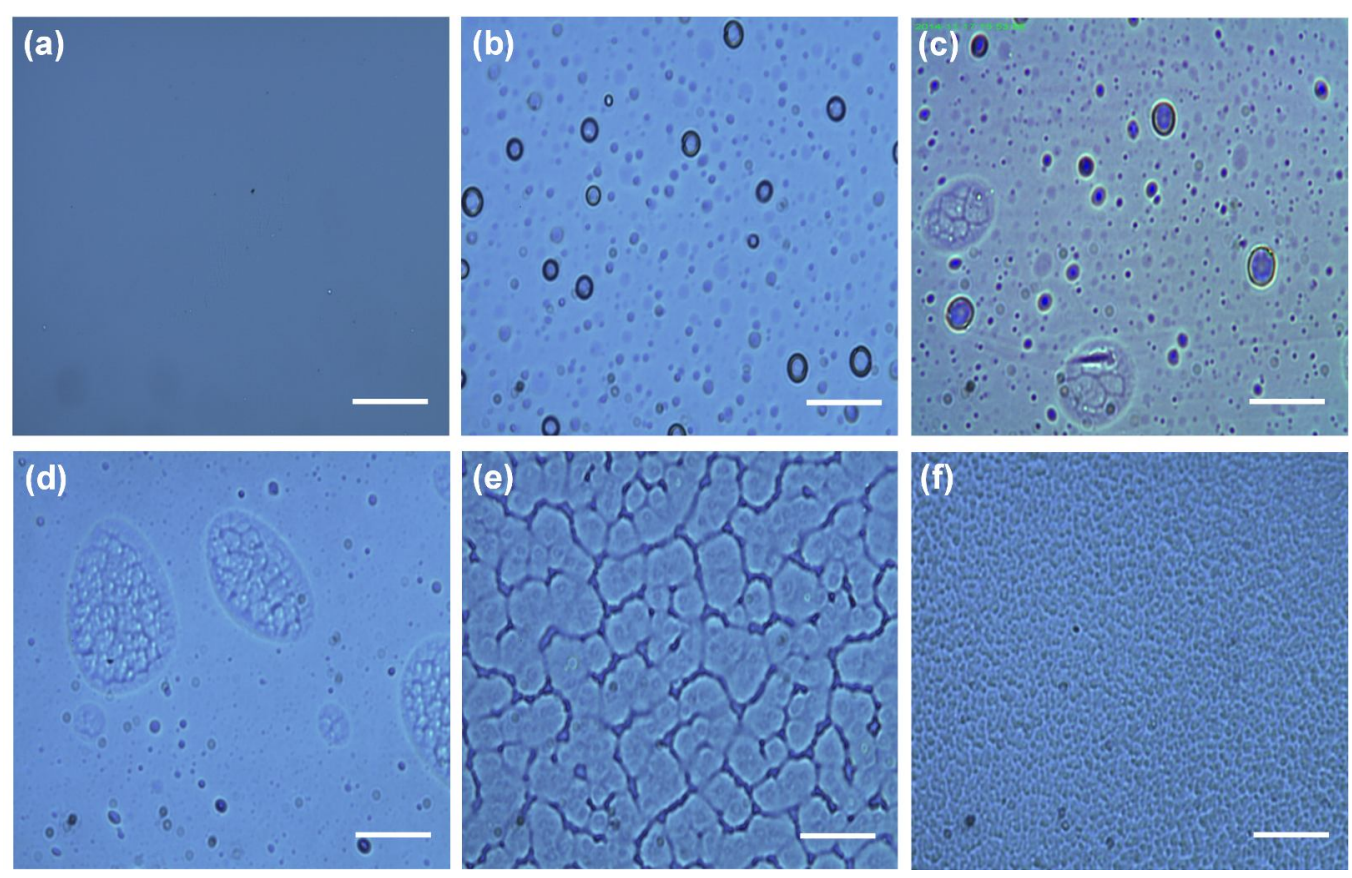

Figure 5 - Dip-coated films observed by transmitted light microscopy at 1000x magnification: (a) Pure SEBS, and increasing F127 concentration to (b) $5 \mathrm{wt} \%$ (c) $10 \mathrm{wt} \%$ (d), $15 \mathrm{wt} \%$ (e) 20 wt $\%$ (f) and pure F127. Scale bars correspond to $20 \mu \mathrm{m}$.
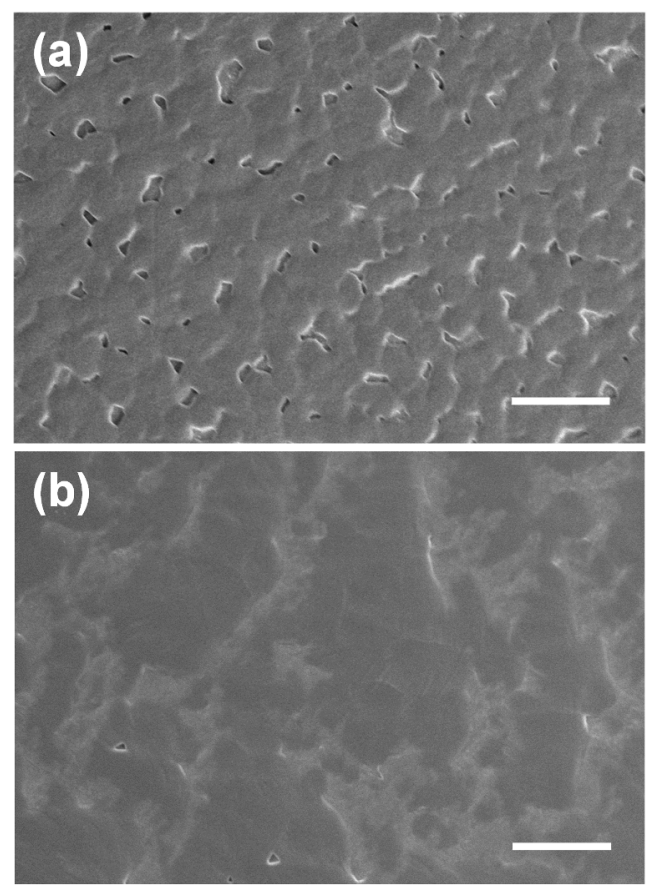

ACS Paragon Plus Environment 
Figure 6 - Dip-coated films observed by SEM in secondary electrons mode and 1000x magnification for the (a) SEBS/F127_20 blend, and (b) pure F127. Scale bars correspond to 20 $\mu \mathrm{m}$.

Figure 7 shows the surface topography of the electrospun fibers observed by SEM. Despite the differences in diameter, it can be observed that pure SEBS (Figure 7a) and SEBS/F127_15 (figure 7b) fibers presented a much smoother surface as compared to SEBS/F127_20 (Figure 7c). This is analogous to what was found for the dip-coated films, where the SEBS/F127_20 blend had the interconnected morphology and a slightly rough surface (Figure 6a). However, it is important to highlight here that for the dip-coated films, the morphology features were in the micron scale, while for the electrospun fibers, the morphology was in the sub-micron scale $(<1 \mu \mathrm{m})$. This difference in order of magnitude can contribute to bring a much more dramatic effect to the surface properties of electrospun mats.

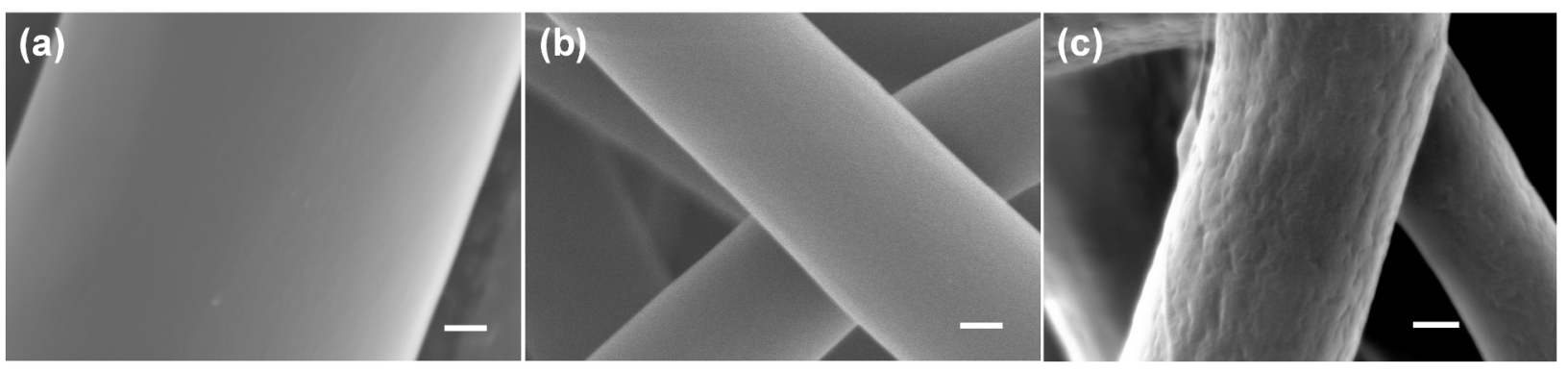

Figure 7 - SEM images of (a) Pure SEBS, (b) SEBS/F127_15 and (c) SEBS/F127_20 at 10.000x magnification. The scale bars correspond to $1 \mu \mathrm{m}$. 
Tapping mode AFM was used to analyze the surface of single fibers at higher magnification. This was possible because the diameter of the fibers was around at least $5 \mu \mathrm{m}$. The experimental scheme and results for phase images are summarized in Figure 8. SEBS presented a typical block copolymer microstructure $^{48}$ with cylindrical-lamellar morphology for the styrene blocks, which appear brighter (Figure 8a). Figures $8 \mathrm{~b}$ and $8 \mathrm{c}$ show two types of fiber surface morphology found for the SEBS/F127_15 blend. In the first type (region 1 - Figure 8b), it was possible to observe a pure SEBS structure, but in this case with a larger presence of cylindrical block morphology with cylinders perpendicular to the surface. Besides SEBS, a second phase dispersed on the surface was observed, which represented the minor component F127. The other type of morphology (region 2) found on SEBS/F127_15 samples is presented in Figure 8c, where it seemed that F127 practically covered the entire surface. There were also circular domains of about $20 \mathrm{~nm}$ in diameter. Similar Pluronic micelle diameter values have been already reported in literature ${ }^{40,43}$. These different degrees of F127 dispersion and concentration for this particular composition can explain the variations in time for the meshes to absorb water in the contact angle tests. With 20 wt\% of F127 (Figure 8d), all the regions analyzed showed a complete cover of the surface withoutthe presence of SEBS domains, but the morphology seemed different from the region 2 of SEBS/F127_15, possibly due to a different organization of F127 micelles with SEBS.

This apparent homogeneous surface, combined with XPS, contact angle, and SEM (Figure 7) results, reinforces the theory that the morphology change observed in dip-coating also occurred during the electrospinning process. A combination of rough/porous structure, chemical composition and blend morphology led to a superhydrophilic electrospun mat. Figure 9 summarizes a possible simplified scheme for the wetting properties of the electrospun mats. The insert shows the hydrophilic PEO segments extended in the water. The differences in fiber 
surface cover resulted in the different absorption times for SEBS/F127_15 and the homogeneously covered SEBS/F127_20 produced constant fast absorption.

Lastly, tensile testing was performed to investigate the effect of hydrophilization on the mechanical properties of the meshes (Table 1). The superhydrophilic composition with 20 wt $\%$ of F127 was chosen and compared with pure SEBS. The mechanical performance is similar to pure SEBS, with an elongation at break greater than 300\% (experimental limit). It is worth noting that these measurements for tensile properties are mainly qualitative, and were performed for the sake of comparison. The results show that there was no deterioration of mechanical properties upon the addition of $20 \mathrm{wt} \%$ of F127.
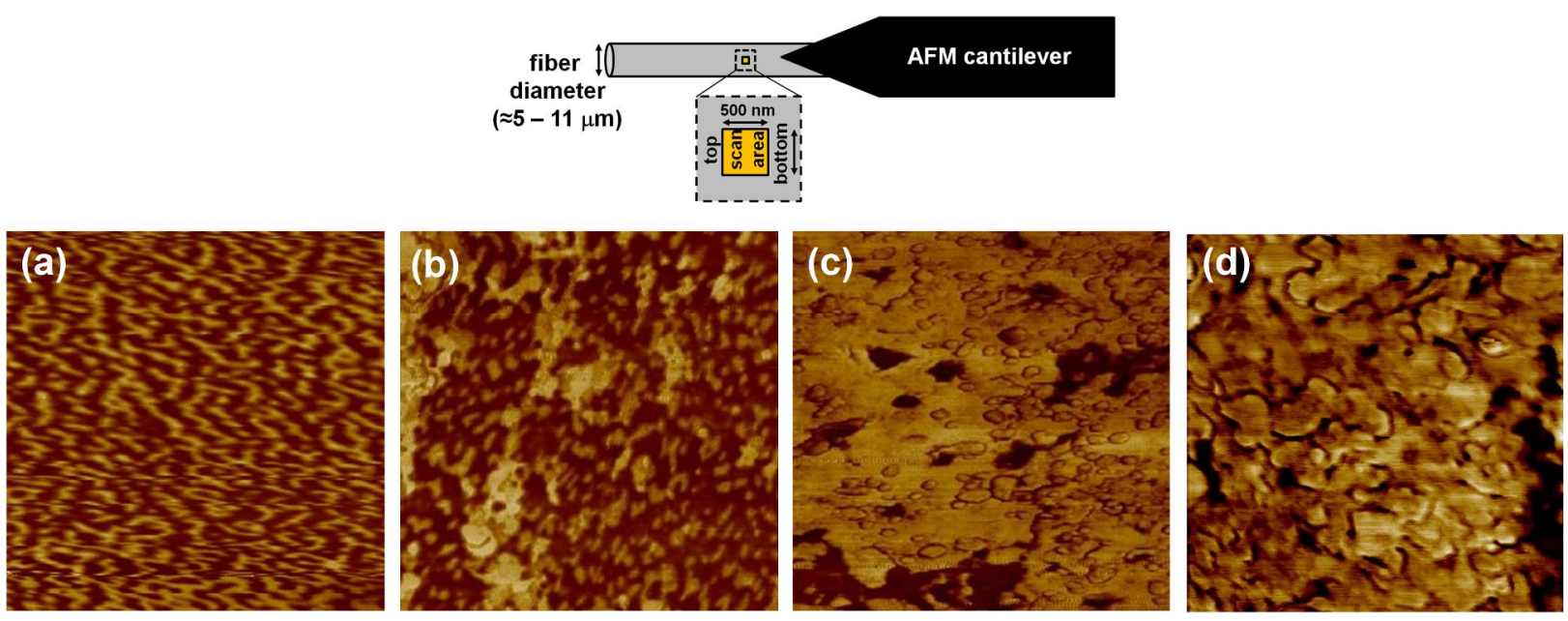

Figure 8 - AFM experimental scheme for electrospun fibers with a scan area of 500nmX500nm; (a-d) Phase images of (a) Pure SEBS, (b) region 1 of SEBS/F127_15, (c) region 2 of SEBS/F127_15, and (d) SEBS/F127_20. 

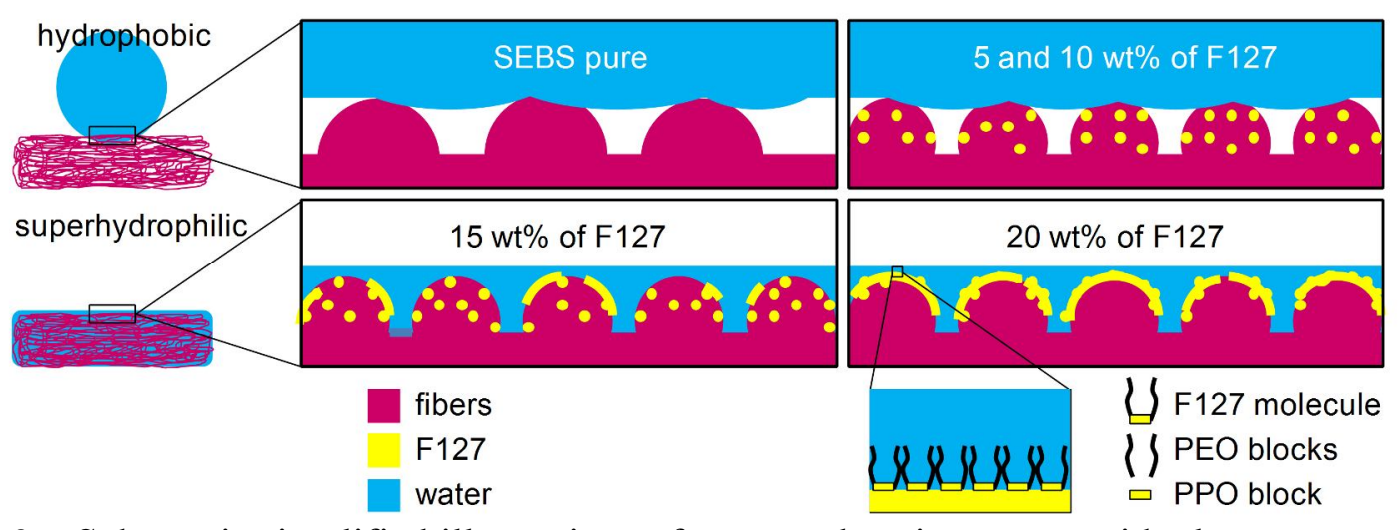

Figure 9 - Schematic simplified illustrations of a water drop in contact with electrospun mats for the hydrophobic and superhydrophilic compositions.

Table 1- Mechanical properties of electrospun mats.

\begin{tabular}{ccc}
\hline Composition & $\begin{array}{c}\text { Tensile Strength } \\
\text { (MPa) }\end{array}$ & $\begin{array}{c}\text { Elongation at } \\
\text { break (\%) }\end{array}$ \\
\hline SEBS & $0.88 \pm 0,10$ & $>300$ \\
SEBS/F127 (80/20) & $0.85 \pm 0,10$ & $>300$ \\
\hline
\end{tabular}

\section{CONCLUSIONS}

Electrospun SEBS mats were highly hydrophobic and flexible. By blending SEBS with 20 wt\% of amphiphilic polymer Pluronic F127, it was possible to obtain superhydrophilic mats and maintain mechanical flexibility. Surface chemical composition results revealed a major segregation of F127 to the surface of the fibers, but this could not fully explain the differences in wetting behavior observed among the mats.

Identical solutions were used to produce dip-coated films. The SEBS/F127 system went through a change in morphology when the concentration reached $20 \mathrm{wt} \%$ of F127, from a typical dispersed phase to a grain-like structure homogeneously distributed across the film. A particular 
micellar structure combining F127 and SEBS must have been formed for this composition. The results for electrospun fibers also suggested that the same switch in morphology occurred, leading to a much more homogenous superhydrophilicity. Complex mixtures of copolymers and solvents may present unique morphologies in their phase diagrams, and therefore an analysis of these features can lead to a better choice of composition and processing conditions for a desired dispersion or property.

Unlike classical polymer processing techniques that produce blends with morphological features (e.g. size of the dispersed phase) in the range of micrometers, electrospinning fibers have diameters generally varying from hundreds of nanometers to a few micrometers, bringing the dispersion of two immiscible polymers to a different order of magnitude. The effect could enhance the property synergy between the two polymers.

\section{ACKNOWLEDGEMENTS}

The authors wish to thank the Natural Sciences and Engineering Research Council of Canada (NSERC) and ÉTS Montreal for their financial support, and professors Sophie Lerouge, Sylvain Cloutier and Vladimir Brailovski from ÉTS Montreal for allowing us to perform contact angle and dip-coating experiments.

\section{REFERENCES}

1. Bhardwaj, N.; Kundu, S. C. Electrospinning: a fascinating fiber fabrication technique. Biotechnol Adv 2010, 28 (3), 325-47.

2. Rutledge, G. C.; Fridrikh, S. V. Formation of fibers by electrospinning. Adv Drug Deliv Rev 2007, 59 (14), 1384-91. 
3. Wu, J.; Wang, N.; Zhao, Y.; Jiang, L. Electrospinning of multilevel structured functional micro-/nanofibers and their applications. Journal of Materials Chemistry A 2013, 1 (25), 72907305.

4. Hutmacher, D. W. Scaffolds in tissue engineering bone and cartilage. Biomaterials 2000, 21 (24), 2529-2543.

5. Gopal, R.; Kaur, S.; Ma, Z.; Chan, C.; Ramakrishna, S.; Matsuura, T. Electrospun nanofibrous filtration membrane. Journal of Membrane Science 2006, 281 (1-2), 581-586.

6. Lin, J.; Shang, Y.; Ding, B.; Yang, J.; Yu, J.; Al-Deyab, S. S. Nanoporous polystyrene fibers for oil spill cleanup. Marine Pollution Bulletin 2012, 64 (2), 347-352.

7. Lee, M. W.; An, S.; Latthe, S. S.; Lee, C.; Hong, S.; Yoon, S. S. Electrospun Polystyrene Nanofiber Membrane with Superhydrophobicity and Superoleophilicity for Selective Separation of Water and Low Viscous Oil. ACS Applied Materials \& Interfaces 2013, 5 (21), 10597-10604.

8. Xue, Z.; Cao, Y.; Liu, N.; Feng, L.; Jiang, L. Special wettable materials for oil/water separation. Journal of Materials Chemistry A 2014, 2 (8), 2445-2460.

9. Ma, Z.; Kotaki, M.; Ramakrishna, S. Electrospun cellulose nanofiber as affinity membrane. Journal of Membrane Science 2005, 265 (1-2), 115-123.

10. Ganesh, V. A.; Nair, A. S.; Raut, H. K.; Walsh, T. M.; Ramakrishna, S. Photocatalytic superhydrophilic TiO 2 coating on glass by electrospinning. RSC Advances 2012, 2 (5), 2067 2072.

11. Srisitthiratkul, C.; Yaipimai, W.; Intasanta, V. Environmental remediation and superhydrophilicity of ultrafine antibacterial tungsten oxide-based nanofibers under visible light source. Applied Surface Science 2012, 259 (0), 349-355.

12. Patankar, N. A. Mimicking the Lotus Effect: Influence of Double Roughness Structures and Slender Pillars. Langmuir 2004, 20 (19), 8209-8213.

13. Nuraje, N.; Khan, W. S.; Lei, Y.; Ceylan, M.; Asmatulu, R. Superhydrophobic electrospun nanofibers. Journal of Materials Chemistry A 2013, 1 (6), 1929-1946.

14. Miyauchi, Y.; Ding, B.; Shiratori, S. Fabrication of a silver-ragwort-leaf-like superhydrophobic micro/nanoporous fibrous mat surface by electrospinning. Nanotechnology 2006, 17 (20), 5151.

15. Nishimoto, S.; Bhushan, B. Bioinspired self-cleaning surfaces with superhydrophobicity, superoleophobicity, and superhydrophilicity. RSC Advances 2013, 3 (3), 671-690.

16. Lim, G. T.; Puskas, J. E.; Reneker, D. H.; Jákli, A.; Horton, W. E. Highly Hydrophobic Electrospun Fiber Mats from Polyisobutylene-Based Thermoplastic Elastomers. Biomacromolecules 2011, 12 (5), 1795-1799.

17. Ito, Y.; Hasuda, H.; Kamitakahara, M.; Ohtsuki, C.; Tanihara, M.; Kang, I. K.; Kwon, O. H. A composite of hydroxyapatite with electrospun biodegradable nanofibers as a tissue engineering material. J Biosci Bioeng 2005, 100 (1), 43-9.

18. Nosonovsky, M. On the Range of Applicability of the Wenzel and Cassie Equations. Langmuir 2007, 23 (19), 9919-9920.

19. Bico, J.; Marzolin, C.; Quéré, D. Pearl drops. EPL (Europhysics Letters) 1999, 47 (2), 220.

20. Callies, M.; Quere, D. On water repellency. Soft Matter 2005, 1 (1), 55-61.

21. Lee, M.; Lee, T.; Park, W. Highly hydrophobic nanofibrous surfaces genearated by poly(vinylidene fluoride). Fibers Polym 2013, 14 (8), 1271-1275. 
22. Ma, M.; Hill, R. M.; Lowery, J. L.; Fridrikh, S. V.; Rutledge, G. C. Electrospun Poly(Styrene-block-dimethylsiloxane) Block Copolymer Fibers Exhibiting Superhydrophobicity. Langmuir 2005, 21 (12), 5549-5554.

23. Zhu, M.; Zuo, W.; Yu, H.; Yang, W.; Chen, Y. Superhydrophobic surface directly created by electrospinning based on hydrophilic material. Journal of Materials Science 2006, 41 (12), 3793-3797.

24. Kim, C. H.; Khil, M. S.; Kim, H. Y.; Lee, H. U.; Jahng, K. Y. An improved hydrophilicity via electrospinning for enhanced cell attachment and proliferation. Journal of Biomedical Materials Research Part B: Applied Biomaterials 2006, 78B (2), 283-290.

25. Ma, M.; Mao, Y.; Gupta, M.; Gleason, K. K.; Rutledge, G. C. Superhydrophobic Fabrics Produced by Electrospinning and Chemical Vapor Deposition. Macromolecules 2005, 38 (23), 9742-9748.

26. Pisuchpen, T.; Chaim-ngoen, N.; Intasanta, N.; Supaphol, P.; Hoven, V. P. Tuning Hydrophobicity and Water Adhesion by Electrospinning and Silanization. Langmuir 2011, 27 (7), 3654-3661.

27. Chandrasekaran, A. R.; Venugopal, J.; Sundarrajan, S.; Ramakrishna, S. Fabrication of a nanofibrous scaffold with improved bioactivity for culture of human dermal fibroblasts for skin regeneration. Biomedical Materials 2011, 6 (1), 015001.

28. Jeon, H.; Kim, G. Preparation and characterization of an electrospun polycaprolactone (PCL) fibrous mat and multi-layered PCL scaffolds having a nanosized pattern-surface for tissue regeneration. Journal of Materials Chemistry B 2014, 2 (2), 171-180.

29. Liu, X.; Lin, T.; Fang, J.; Yao, G.; Zhao, H.; Dodson, M.; Wang, X. In vivo wound healing and antibacterial performances of electrospun nanofibre membranes. Journal of Biomedical Materials Research Part A 2010, 94A (2), 499-508.

30. Cho, W. J.; Kim, J. H.; Oh, S. H.; Nam, H. H.; Kim, J. M.; Lee, J. H. Hydrophilized polycaprolactone nanofiber mesh-embedded poly(glycolic-co-lactic acid) membrane for effective guided bone regeneration. Journal of Biomedical Materials Research Part A 2009, 91 A (2), 400-407.

31. Cécile, C.; Hsieh, Y.-L. Hydrophilic polystyrene/maleic anhydride ultrafine fibrous membranes. J Appl Polym Sci 2010, 115 (2), 723-730.

32. Lim, H. S.; Park, S. H.; Koo, S. H.; Kwark, Y.-J.; Thomas, E. L.; Jeong, Y.; Cho, J. H. Superamphiphilic Janus Fabric. Langmuir 2010, 26 (24), 19159-19162.

33. Kim, K.; Yu, M.; Zong, X.; Chiu, J.; Fang, D.; Seo, Y.-S.; Hsiao, B. S.; Chu, B.; Hadjiargyrou, M. Control of degradation rate and hydrophilicity in electrospun non-woven poly (D, L-lactide) nanofiber scaffolds for biomedical applications. Biomaterials 2003, 24 (27), 4977 4985.

34. Liu, N.-h.; Pan, J.-f.; Miao, Y.-E.; Liu, T.-X.; Xu, F.; Sun, H. Electrospinning of poly ( $\varepsilon$ caprolactone-co-lactide)/Pluronic blended scaffolds for skin tissue engineering. Journal of Materials Science 2014, 49 (20), 7253-7262.

35. Vasita, R.; Mani, G.; Agrawal, C. M.; Katti, D. S. Surface hydrophilization of electrospun PLGA micro-/nano-fibers by blending with Pluronic ${ }^{\circledR}$ F-108. Polymer 2010, 51 (16), 3706-3714.

36. Valiquette, D.; Pellerin, C. Miscible and Core-Sheath PS/PVME Fibers by Electrospinning. Macromolecules 2011, 44 (8), 2838-2843.

37. Li, G.; Zhao, Y.; Lv, M.; Shi, Y.; Cao, D. Super hydrophilic poly(ethylene terephthalate) (PET)/poly(vinyl alcohol) (PVA) composite fibrous mats with improved mechanical properties 
prepared via electrospinning process. Colloids and Surfaces A: Physicochemical and Engineering Aspects 2013, 436 (0), 417-424.

38. Wang, Y.-q.; Wang, T.; Su, Y.-l.; Peng, F.-b.; Wu, H.; Jiang, Z.-y. Remarkable Reduction of Irreversible Fouling and Improvement of the Permeation Properties of Poly(ether sulfone) Ultrafiltration Membranes by Blending with Pluronic F127. Langmuir 2005, 21 (25), 11856-11862.

39. Lee, J. H.; Ju, Y. M.; Kim, D. M. Platelet adhesion onto segmented polyurethane film surfaces modified by addition and crosslinking of PEO-containing block copolymers. Biomaterials 2000, 21 (7), 683-691.

40. Alexandridis, P.; Alan Hatton, T. Poly(ethylene oxide)-poly(propylene oxide)poly(ethylene oxide) block copolymer surfactants in aqueous solutions and at interfaces: thermodynamics, structure, dynamics, and modeling. Colloids and Surfaces A: Physicochemical and Engineering Aspects 1995, 96 (1-2), 1-46.

41. Kell, M. Structural studies of aqueous solutions of PEO - PPO - PEO triblock copolymers, their micellar aggregates and mesophases; a small-angle neutron scattering study. Journal of Physics: Condensed Matter 1996, 8 (25A), A103.

42. Ghofraniha, N.; Tamborini, E.; Oberdisse, J.; Cipelletti, L.; Ramos, L. Grain refinement and partitioning of impurities in the grain boundaries of a colloidal polycrystal. Soft Matter 2012, 8 (23), 6214-6219.

43. Tamborini, E.; Ghofraniha, N.; Oberdisse, J.; Cipelletti, L.; Ramos, L. Structure of Nanoparticles Embedded in Micellar Polycrystals. Langmuir 2012, 28 (22), 8562-8570.

44. Rungswang, W.; Kotaki, M.; Shimojima, T.; Kimura, G.; Sakurai, S.; Chirachanchai, S. Existence of microdomain orientation in thermoplastic elastomer through a case study of SEBS electrospun fibers. Polymer 2011, 52 (3), 844-853.

45. Rungswang, W.; Kotaki, M.; Shimojima, T.; Kimura, G.; Sakurai, S.; Chirachanchai, S. Directing Thermoplastic Elastomer Microdomain Parallel to Fiber Axis: A Model Case of SEBS with Benzoxazine through $\pi-\pi$ Stacking. Macromolecules 2011, 44 (23), 9276-9285.

46. Rungswang, W.; Kotaki, M.; Shimojima, T.; Kimura, G.; Sakurai, S.; Chirachanchai, S. Role of surfactant on inducing specific microdomains of block copolymer: An example case from polystyrene-b-poly(ethylene-co-1-butene)-b-polystyrene (SEBS) electrospun thermoplasticelastomer fiber containing polyethylene glycol lauryl ether (PGLE). Polymer 2014, 55 (8), 20682076.

47. Shi, Q.; Ye, S.; Kristalyn, C.; Su, Y.; Jiang, Z.; Chen, Z. Probing Molecular-Level Surface Structures of Polyethersulfone/Pluronic F127 Blends Using Sum-Frequency Generation Vibrational Spectroscopy. Langmuir 2008, 24 (15), 7939-7946.

48. Wang, Y.; Hong, X.; Liu, B.; Ma, C.; Zhang, C. Two-Dimensional Ordering in Block Copolymer Monolayer Thin Films upon Selective Solvent Annealing. Macromolecules 2008, 41 (15), 5799-5808. 
Table of Contents Graphic

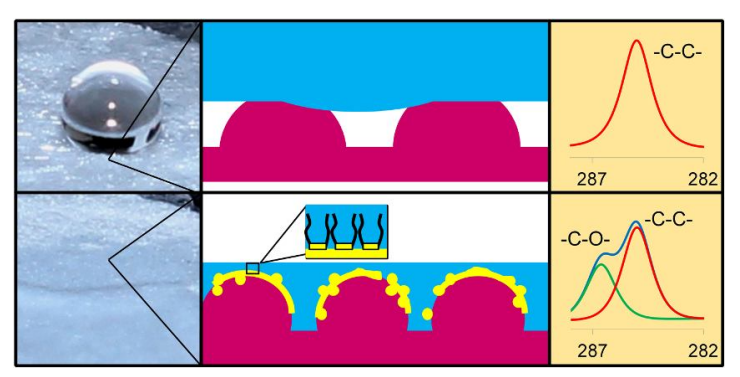


Figure 1 - Water contact angle for the electrospun mats $(\bullet)$ and dip-coated films $(0)$ as a function of F127 concentration in the SEBS/F127 blends. The insert shows the vials containing each solution. $157 \times 95 \mathrm{~mm}(300 \times 300 \mathrm{DPI})$ 


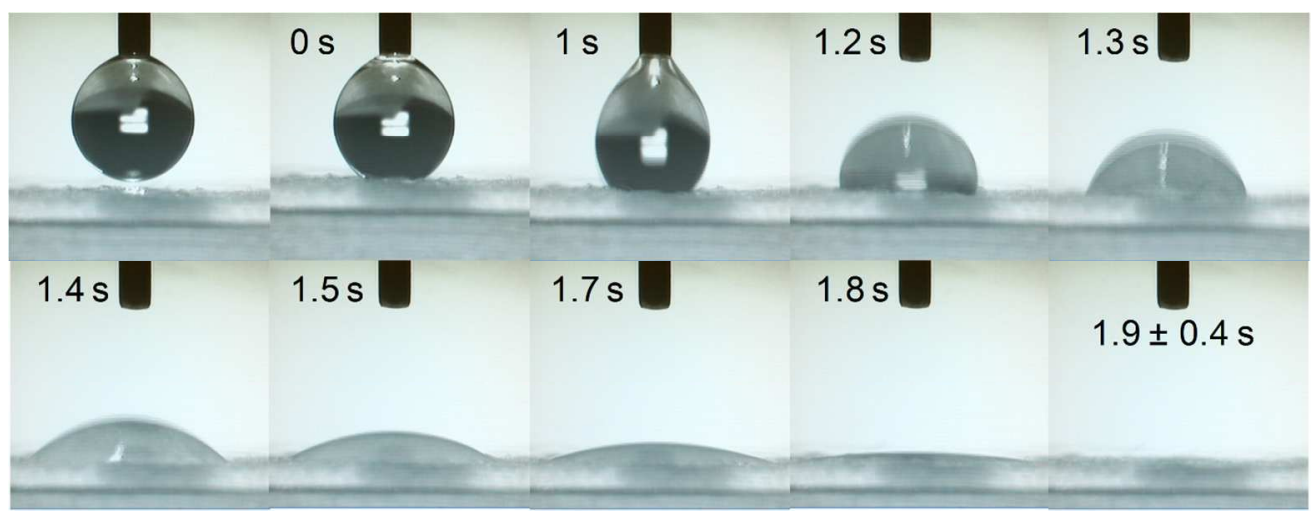

Figure 2 - Water droplet fast spreading for the superhydrophilic SEBS/F127_20 electrospun mat. $119 \times 45 \mathrm{~mm}(300 \times 300 \mathrm{DPI})$ 


\section{Page 27 of 35}

\section{Langmuir}
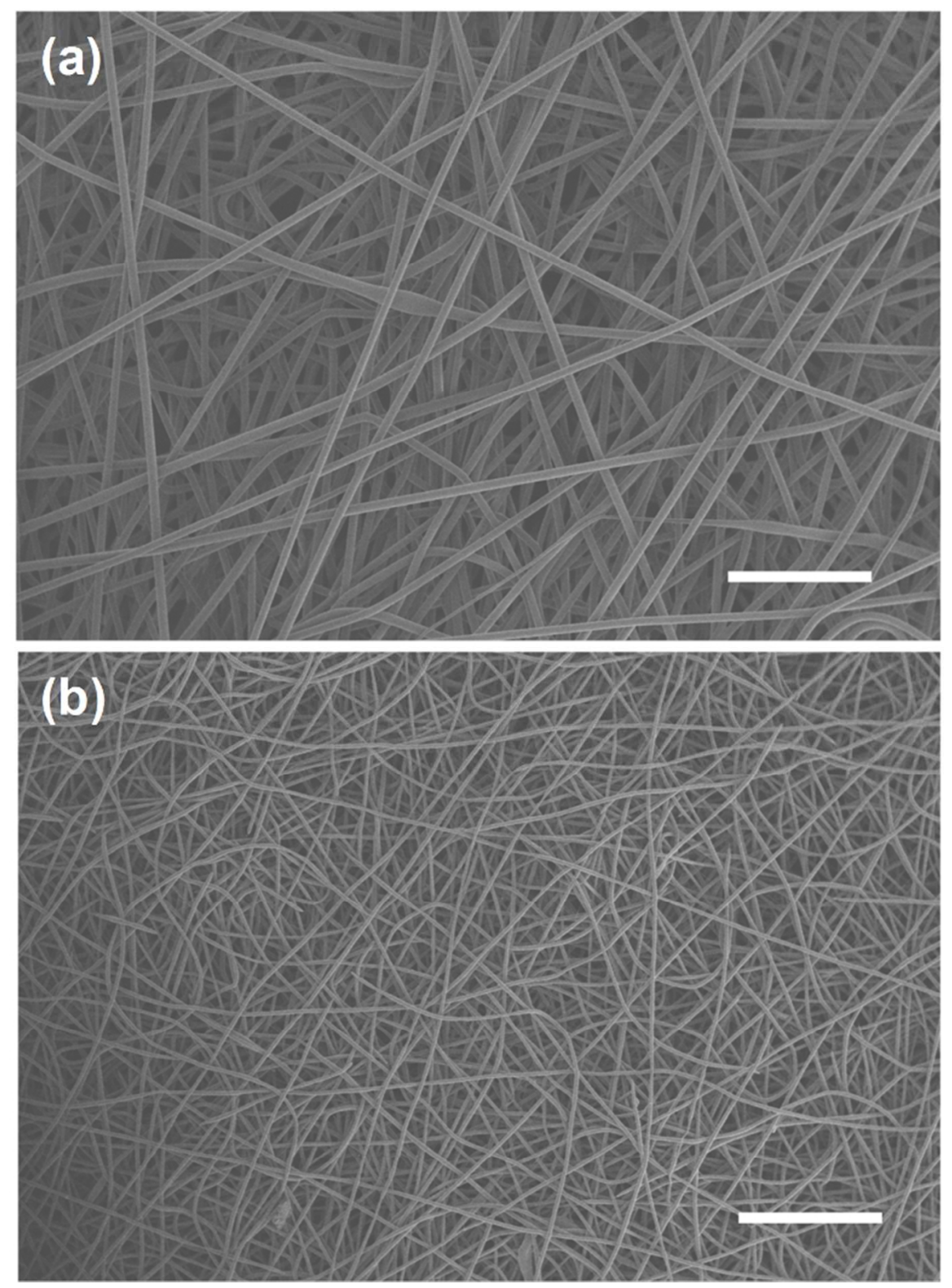

Figure 3 - Electrospun fibers observed by SEM with 100x magnification: (a) pure SEBS and (b) SEBS/F127_20. Scale bars correspond to $200 \mu \mathrm{m}$ $65 \times 89 \mathrm{~mm}(300 \times 300$ DPI $)$ 


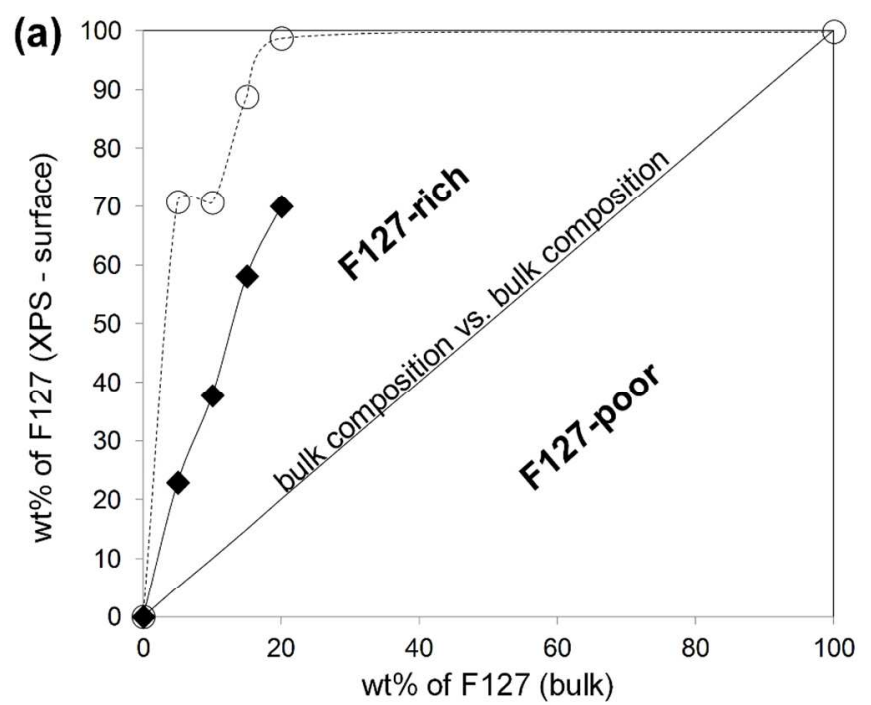

\section{(b)}
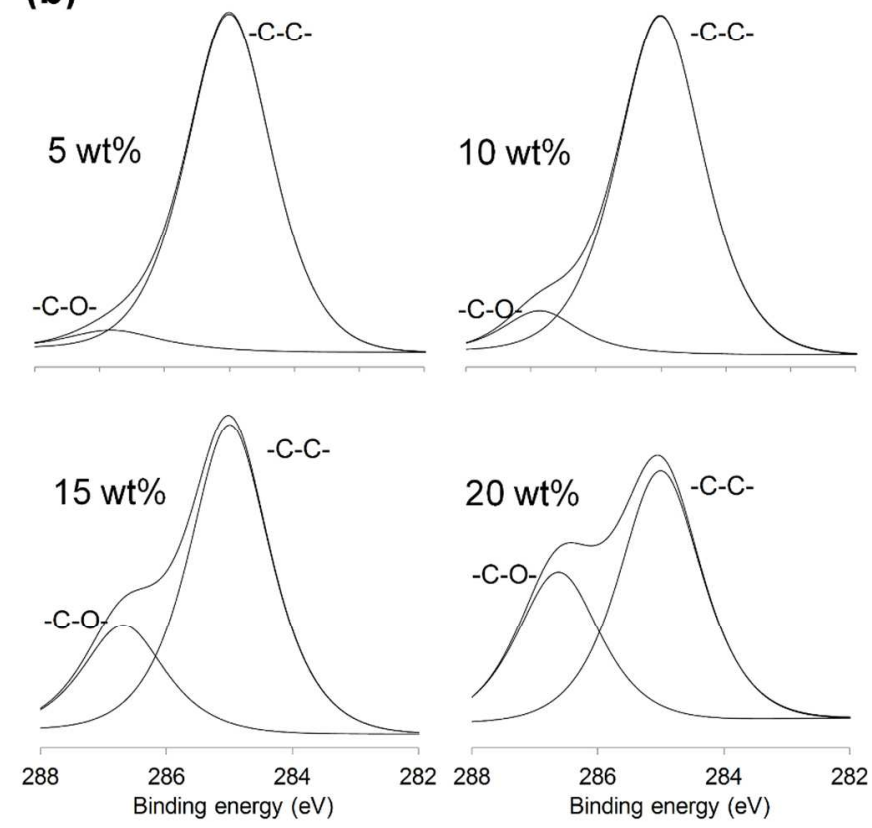

Figure 4 - XPS results: (a) measured \% of oxygen atoms converted in wt $\%$ of $F 127$ vs. bulk wt $\%$ of $F 127$ for the electrospun mats $(\bullet)$ and dip-coated films (o); (b) High resolution XPS spectra for the electrospun mats of SEBS/F127 with 5, 10, 15 and 20 wt\% of F127. $80 \times 141 \mathrm{~mm}(300 \times 300 \mathrm{DPI})$ 

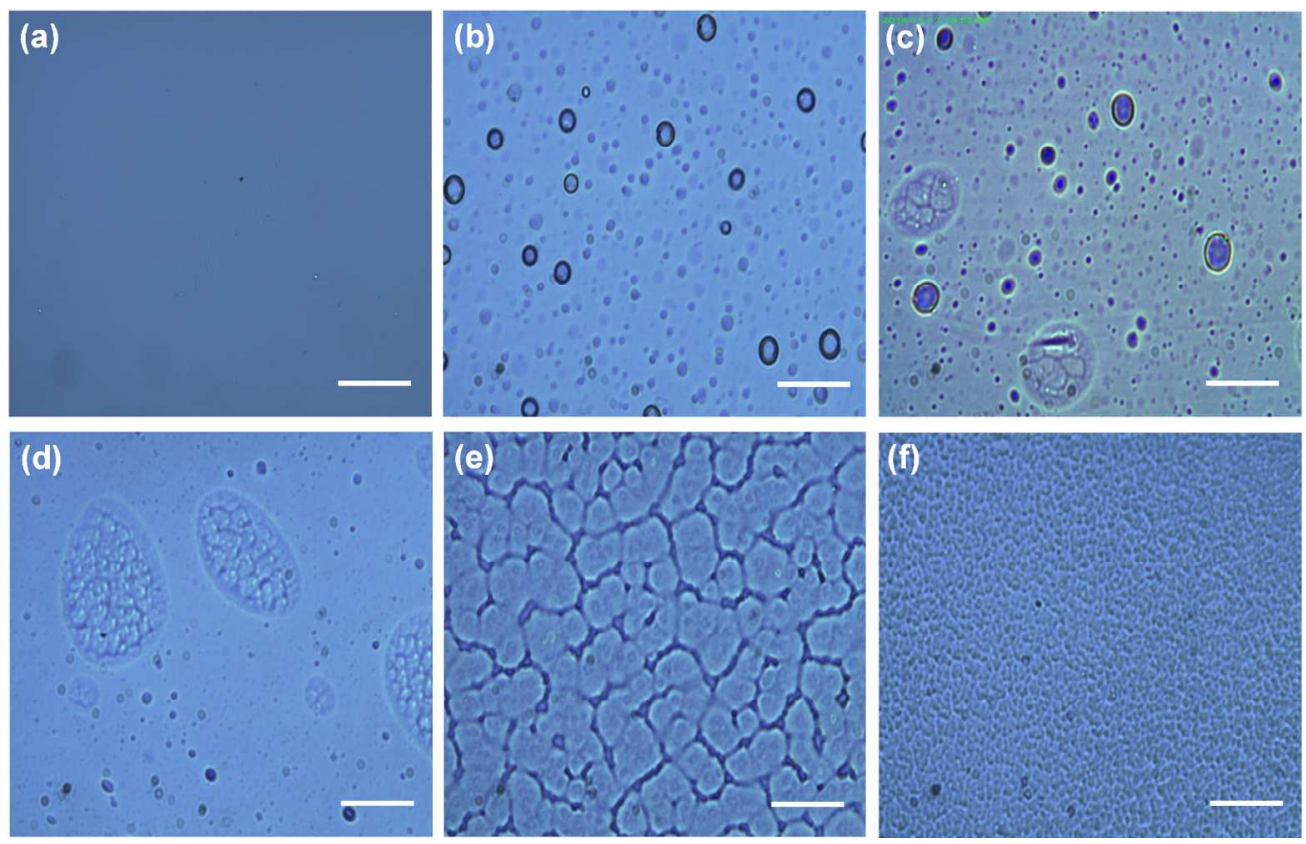

Figure 5 - Dip-coated films observed by transmitted light microscopy at 1000x magnification: (a) pure SEBS, and increasing F127 concentration to (b) 5 wt\% (c) 10 wt\% (d), 15 wt\% (e) 20 wt\% (f) and pure F127. Scale bars correspond to $20 \mu \mathrm{m}$. $136 \times 86 \mathrm{~mm}(300 \times 300 \mathrm{DPI})$ 

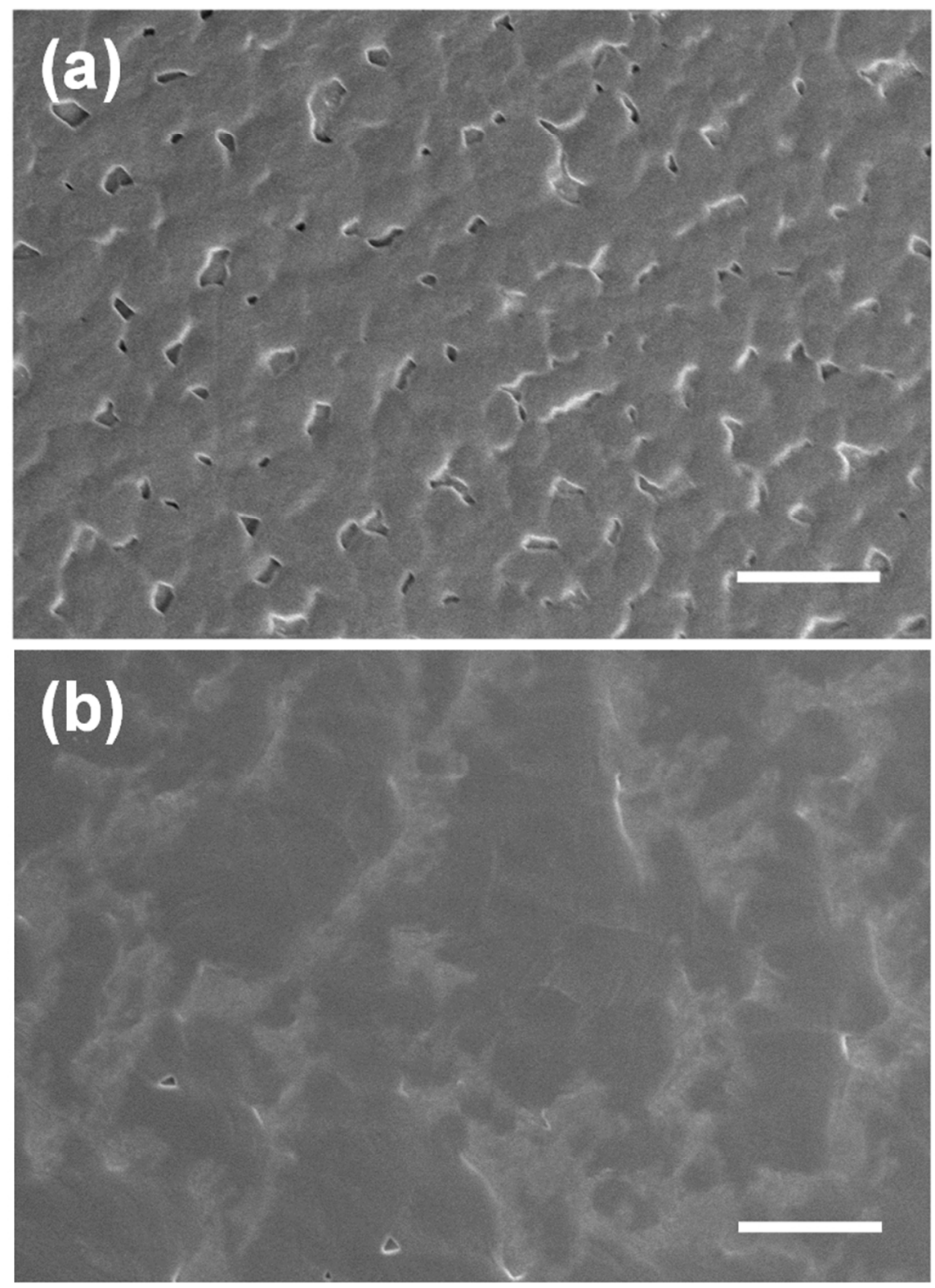

Figure 6 - Dip-coated films observed by SEM in secondary electrons mode and 1000x magnification for the (a) SEBS/F127_20 blend and (b) pure F127. Scale bars correspond to $20 \mu \mathrm{m}$. $65 \times 88 \mathrm{~mm}(300 \times 300$ DPI $)$ 


\section{Page 31 of 35}

1 2 3 4 5 6 7

8 9 10 11

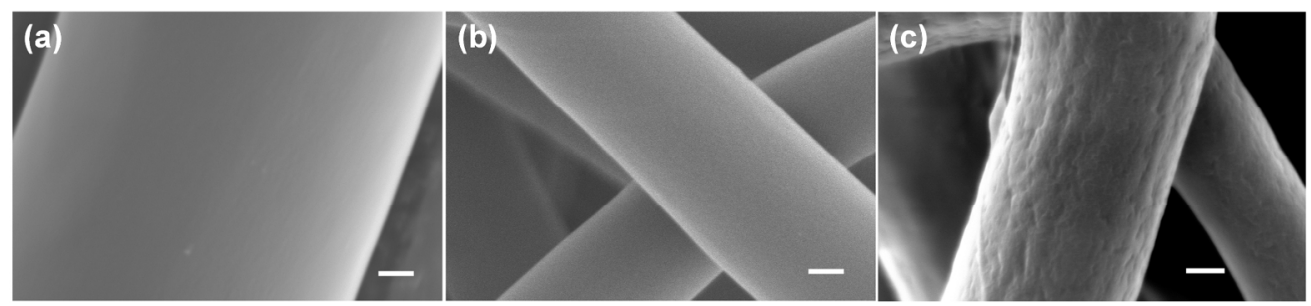

Figure 7 - SEM images of (a) Pure SEBS, (b) SEBS/F127_15 and (c) SEBS/F127_20 at 10.000x magnification. The scale bars correspond to $1 \mu \mathrm{m}$. $165 \times 37 \mathrm{~mm}(300 \times 300 \mathrm{DPI})$ 
Figure 8 - AFM experiments scheme for electrospun fibers with a scan area of 500nmX500nm; (a-d) Phase images of (a) Pure SEBS; (b) region 1 of SEBS/F127_15; (c) region 2 of SEBS/F127_15 and (d) SEBS/F127_20. $164 \times 62 \mathrm{~mm}(300 \times 300$ DPI $)$ 


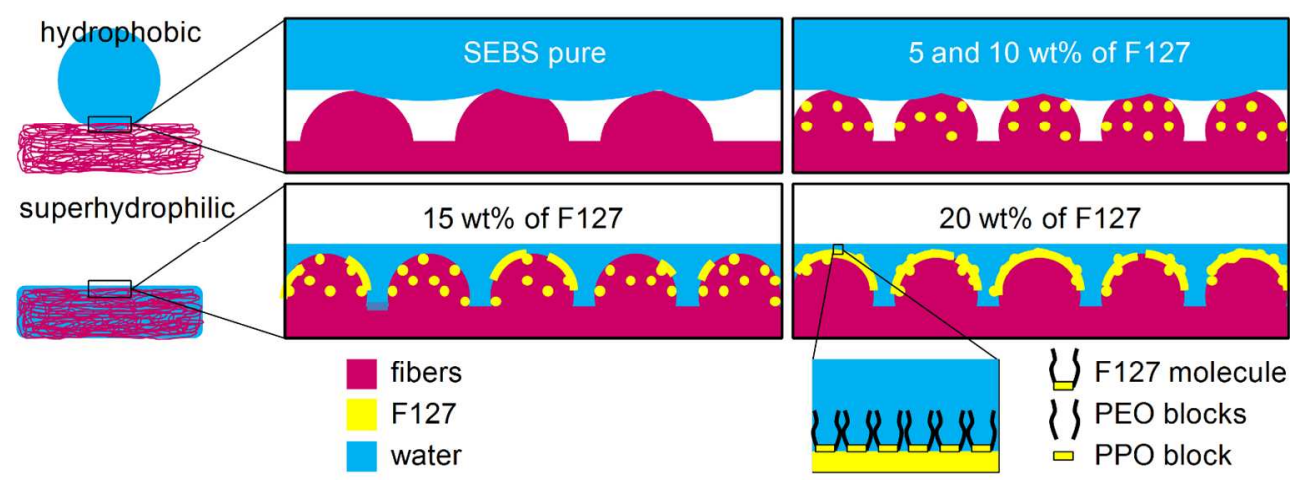

Figure 9 - Schematic simplified illustrations of a water drop in contact with electrospun mats for the hydrophobic and superhydrophilic compositions $142 \times 52 \mathrm{~mm}(300 \times 300 \mathrm{DPI})$ 


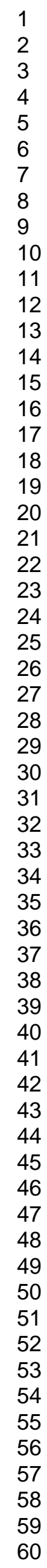

\begin{tabular}{ccc}
\hline Composition & $\begin{array}{c}\text { Tensile Strength } \\
(\mathrm{MPa})\end{array}$ & $\begin{array}{c}\text { Elongation at } \\
\text { break (\%) }\end{array}$ \\
\hline SEBS & $0.88 \pm 0,10$ & $>300$ \\
SEBS/F127 (80/20) & $0.85 \pm 0,10$ & $>300$ \\
\hline
\end{tabular}

10

12

13

14

15

17

18

19

20

22

24

25

26

27

29

30

33

34

35

36

39

40

41

42

43

46

47

48

49

50 


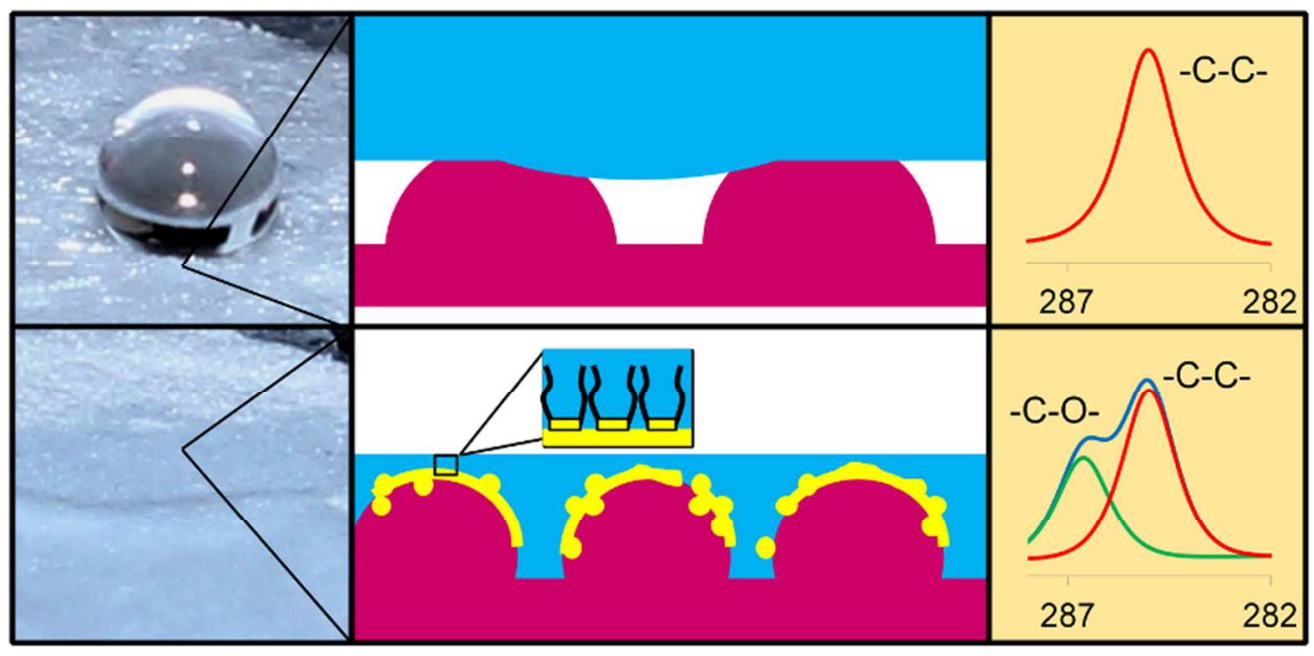

Table of Contents Graphic $72 \times 35 \mathrm{~mm}(300 \times 300$ DPI $)$ 